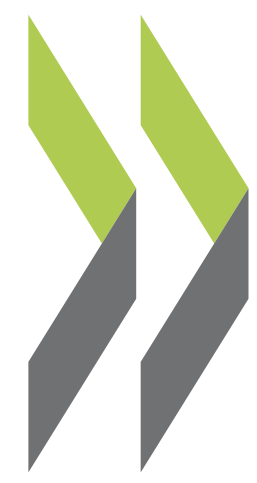

PEB Exchange, Programme on Educational Building 2003/07

\title{
The Urban Complex in Cattolica, Italy
}

\section{OECD}




\section{THE URBAN COMPLEX IN CATTOLICA, ITALY}

The Italian city of Cattolica has developed an urban complex, the Piazza della Repubblica, providing a wide range of services to the public. In renovated facilities, the complex provides a modern and rational architectural setting based on the idea of the traditional town square or "piazza", an area of interaction and exchange characteristic of Italian cities.

A primary school, a community cultural centre housing the municipal library, and a theatre are but a few of the various facilities located around the vast circular piazza originally used as a market and an open-air theatre. A newly built outdoor theatre made of masonry is now used for various events in summer. The architectural complex surrounding the piazza also includes a centre for music studies, a vocational training school, a dance school, visual arts workshops, the Civic University, a fitness gym, a post office, the Public Health Office, a café, a pub and an underground supermarket with ample parking. The piazza is an exclusively pedestrian area.

Developing the complex, the municipal government of Cattolica, which is one of the main tourist centres of the Emilia-Romagna Region, ensured that the city's tourist infrastructure includes a cultural dimension. During the summer season, in addition to its resident population of 16000 , some 250000 visitors come to stay in this seaside resort.

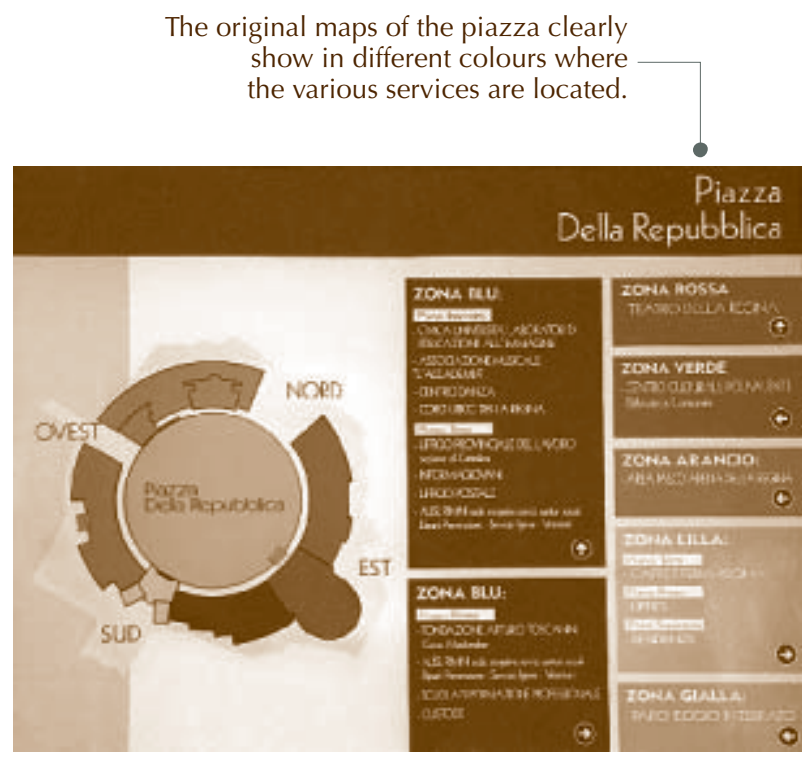

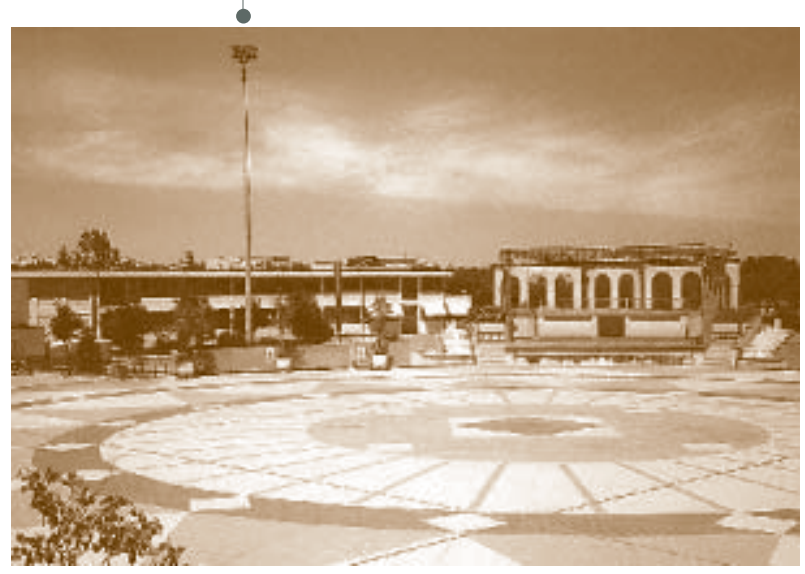

\section{The Repubblica primary school}

The Repubblica school was constructed in 1966 for students aged 6-10. As part of the plan for reorganising and rationalising the city's school system in 1993, the school was renovated, following a design by Daniele Fabbri, into a combined day-care centre (ages 3-5) and elementary school (ages 6-10). It is now equipped with laboratories, workshops and other facilities for integrated activities and remedial instruction. There are a total of 400 pupils in 16 classes.

The overall surface area of the building is $1600 \mathrm{~m}^{2}$ on three levels: one underground, one raised above ground level and a first floor. Children have access to a large garden area with pine trees.

The entire building was renovated at a cost of EUR 1500000.

\section{The community cultural centre}

Built between 1979 and 1983, the community cultural centre's design is still highly functional and user-friendly. It now provides a broad range of services - which in recent years have become strongly focused on multimedia - that include a municipal library, a large newspaper and periodical collection, an exhibition area (the Santa Croce Gallery) and the Museo della Regina, a museum with a section on archaeology and another on the history of seamanship, which was the city's primary activity until the advent of the tourist industry.

The centre was designed by Pier Luigi Cervellati, an architect who is well-known for renovating historic city centres (in particular Bologna). It is a large, semicircular hall-like building made of reinforced-concrete that faces onto the piazza and is fronted by a portico, with an overall surface area of approximately $2000 \mathrm{~m}^{2}$ on two levels. The centre is air-conditioned, has a closed-circuit audio-television 
link for recording and retransmitting events and performances, and is equipped with electronic burglar-alarm and anti-theft systems. Inside, it has an open-space design and is divided into separate areas that interact and communicate with each other in an arrangement that effectively expresses the multifunctional nature of the centre. Since the 1970s, this multifunctionality has been a key concept that has inspired policies for promoting numerous cultural activities and events and for establishing institutions equipped with technological systems able to provide modern cultural services.

\section{The municipal library}

The municipal library has been a key institution ever since it was established, serving both schools, the population of Cattolica and tourists. The library was founded by the local school association in 1914 at a different location in the city and in 1982 was transferred to the new community cultural centre. It is also appreciated by tourists who can borrow books by paying a membership fee.

The library currently has some 55000 volumes in all fields, of which 17500 are shelved in areas open to the public, while the remaining books are kept in closed stacks. Some 6500 multimedia documents are available in the media centre. The library already had some 5000 volumes of books by the 1940s, but two thirds of the collection was destroyed during the Second World War. The 1500 volumes saved during the war cover approximately a century and a half of Italian publishing, and are still part of the municipal library's holdings.

It is easy to consult and borrow items, which are made available immediately. There are seven computer consoles for consulting the on-line catalogue. Trained staff are present continuously during opening hours to help users to consult catalogues and locate materials.

There is a reference service intended for students of all levels, from primary school pupils to undergraduates and researchers, but also for anyone wishing to request infor-

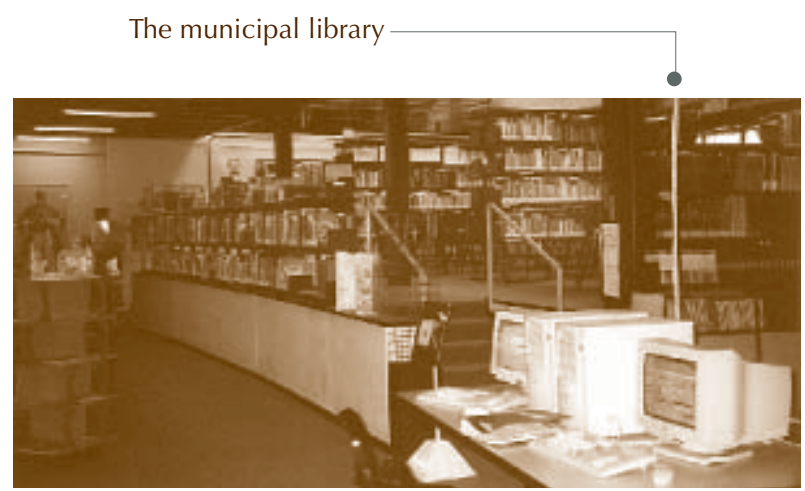

mation of any kind. The library also provides photocopying services and services for reproducing photographs in the cultural centre's archive and for duplicating the audiovisual materials produced by the cultural centre.

\section{The Teatro della Regina}

Adjoining the community cultural centre is the Teatro della Regina, another project by Pier Luigi Cervellati. Inaugurated in 1996, it was the first completely new theatre designed and built in Italy since World War II. It is equipped with state-of-the-art technology and has a total of 700 seats and a spacious foyer that can be used for meetings and conferences. Cattolica's new theatre is a symbol of its commitment to culture as a means of civic development.

Cervellati created an elegant and modern design that combines the basic plan of the traditional Italian theatre with the functionality and versatility required for modern stage productions. The theatre's design reproduces the classic horseshoe shape characteristic of traditional Italian theatres. Two tiers of boxes, topped by a spacious balcony forming a third tier, enclose the orchestra area panelled with blond wood, giving the theatre outstanding acoustics.

The Teatro della Regina with the municipal library to its left

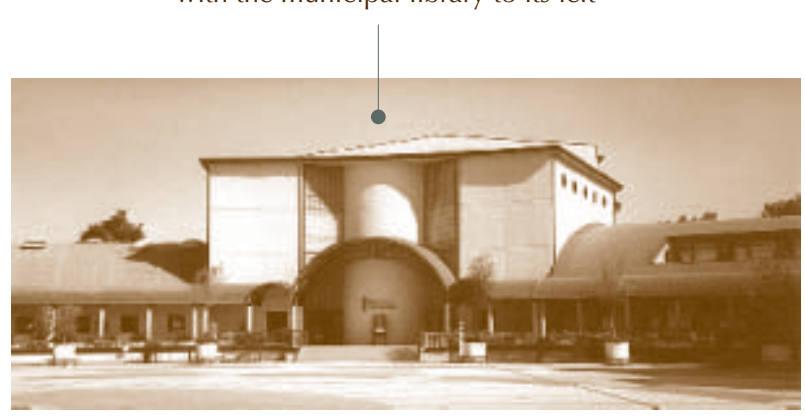

To contact the City of Cattolica:

Piazza Roosevelt 5

47841 Cattolica $R \mathrm{~N}$

Tel.: 390541966511

Web site: www.cattolica.net

The Repubblica school can be contacted at:

Piazza Repubblica 8

47841 Cattolica RN

Tel.: 390541954209

E-mail:ddcattolica@rimini.com

See a $360^{\circ}$ moving view of the Piazza at: www.cattolica.net/retecivica/italiano/ente/visital index.php3?RESEARCH_PAGE=piazza_repubblica.htm 